\title{
Understanding Preferences in Tourism Email Marketing
}

\author{
Elide Garbani-Nerini ${ }^{(\varpi)}(\mathbb{D}$, Elena Marchiori (D), Rossella Reale, \\ and Lorenzo Cantoni 10 \\ Università della Svizzera italiana, Via Buffi 13, 6900 Lugano, Switzerland \\ elide.garbani.nerini@usi.ch
}

\begin{abstract}
Nowadays, advanced tools allow the personalization of email communication with tourism clients or prospects based on explicit (e.g. name, age, language, country) and implicit indicators (e.g. ranking of activity in the opening rate of the newsletter, browsing preferences, online preferences provided by cookies, etc.). However, knowing how audiences react to emails allows Destination Marketing Organizations (DMOs) to create content clusters for personalized communication. The purpose of this study is to empirically investigate the preferences on tourism email marketing of different audiences based on a specific explicit indicator, namely the language chosen by users to receive communications by a DMO. A content analysis on a longitudinal dataset based on 131 newsletter messages sent between 2018 and 2021 to more than $50^{\prime}$ 000 contacts by a DMO in Switzerland was performed. Results show that content should be adapted to different audiences speaking different languages instead of providing just a translation. Specifically, the German-speaking audience seems to be more inclined to messages that focus on winter sports and hiking, the Italian-speaking audience to news about hiking and information on COVID-19, the French-speaking audience to news about promotions, while the English-speaking audience to contents on discounts and COVID-19-related. These results provide an important contribution to studies on tourism personalization of communication in the context of email marketing, suggesting the role of content adaptation according to the language and cultural background of the audience. DMO managers can also benefit from this research in understanding how to address a similar study on their datasets and compare the emerged content clusters.
\end{abstract}

Keywords: Email marketing - Tourism personalization - Tourism preferences · Customer value creation

\section{Introduction}

Email is an important communication channel in marketing and is still one of the most commonly used by many industries, including tourism, and, in this specific case, DMOs. The main reasons for that, as highlighted by many authors in the literature, is its cost-efficiency and its speed, in terms both of reaction by customers/prospects and of development of marketing campaigns [1-4]. Generally, in email marketing campaigns, success is determined by using specific metrics such as open rate (OR), i.e. the 
percentage of addressees who have opened the message, and click-through rate (CTR), i.e. the percentage of those who have clicked on at least one link out of the people who had received the email [5]. Clicking on a link represents the voluntary act of interest/curiosity that addressees show towards the sender of the message as they select topics that they are interested in learning more about. In the industry, email marketing is usually managed using special tools (such as the popular tools named Mailchimp, MailUp, Salesforce). These tools provide statistics on campaign performances and audiences, allowing for a first customer segmentation. Extending this analysis could bring interesting insights on how to segment customers more efficiently. DMOs have in fact access to several data when it comes to email campaigns and audiences and this makes it interesting to study the potential to develop this channel with personalization to improve communication practices. However, few companies and DMOs are willing to share such performance data, as they represent a competitive and strategic asset. Thus, the lack of studies in this area can be related to this limited access to data. This study emphasizes the importance of studying email marketing performance by bringing insights from a longitudinal study on newsletters in tourism. Results underline how to identify more personalized content clusters for different audiences thanks to the analysis of a specific explicit indicator, namely the language chosen by users to receive communications by a DMO in relation with an implicit indicator, namely click behavior.

\section{Literature Review}

\subsection{Segmentation in Email Marketing}

Studies on email marketing consider audience segmentation as key to a successful interaction with clients, reflected with high open, click-through and conversion rates [3, 4, 6-8]. In particular, Mailchimp, an integrated marketing platform, compared the results of its users' segmented campaigns with those of the same users' non-segmented campaigns: segmented campaigns performed better, with higher open, unique open, and click rate, and lower bounces and unsubscriptions [6]. There are several methods for customer/audience segmentation that have been studied in the literature. There are methods that use customer details [8] such as demographic and lifestyle data, others use data product, others customer/audience behaviors - the most popular models being the RFM model, clustering customers according to their purchase's "recency", "frequency" and "monetary" value, and the customer lifetime value (CLV) model, which determines customers' importance level based on a calculation of the net cash flow generated by the customers $[4,9]$. The market standards with respect to how to classify contacts can be divided into two main approaches: i) explicit indicators on users/audience (e.g.: name, age, language, country), that is information voluntarily provided by users; and ii) implicit indicators on users/audience (e.g.: ranking of activity in the opening rate of the newsletter, browsing preferences, online preferences provided by cookies, etc.), that is information that can be inferred from users' interaction with emails and connected web pages. In general, different data sources can be used and combined to create more efficient segmentations and consequently more efficient communication [8]. 
Segmentation is the foundation for personalized email marketing campaigns, one of the main trends in email marketing [10], as the format and content of messages can be adapted to different segments and eventually for a given individual. Similarly to segmentation, personalized emails have been found to increase campaign performance $[11,12]$.

\subsection{Personalization in Tourism}

Personalization has been defined by Jackson [13] as "a way of doing things. Personali [z]ation derives customer information to provide consistent, timely and relevant individuali[z]ed interactions and offers to each customer across all touchpoints that increases customer loyalty and lifetime value" (p 26). In general, however, personalization is not always easily applied and, above all, univocally understood and interpreted [14]. In tourism, personalization has been studied and applied to different areas, such as travel planning and recommender systems. Existing recommender systems have been analyzed in the literature $[15,16]$, and new ones have been proposed: Missaoui S. [17] presented the mobile app LOOKER, a recommender system based on a user generated content-based filtering algorithm; Amer-Yahia et al. [18] developed an interactive framework that generates customized travel packages for individuals or for groups of travelers; De Carolis et al. [19] analyzed the potential of social robots in providing effective tourism recommender systems; Wang [20] proved how including data on online behavior of potential travelers can improve personalized recommendations systems; Ravi et al. [21] worked on an algorithm- and hybrid user clusteringbased travel planning system for personalized point of interest recommendation; Choi et al. [22] presented a recommender system to help tourists create a personalized travel plan based on collaborative and constraint satisfaction filtering; Chen et al. [23] developed a method to design personalized travel routes for tourists by combining user clustering, improved genetic, and rectangular region path planning algorithms. Personalization can be used also to provide specific information to tourists with particular needs, as proposed by Ribeiro et al. [24] with their personalized system to assist mobility disabled tourists during their visit and activities.

In cultural tourism, personalization can help enhance the dialogue between culture providers and cultural tourists. Ross [25]'s study on Alentejo in Portugal showed that more personalized individual-based guiding activities can be used in co-creating experiences by cultural tourism providers to deliver more meaningful experiences also appealing to visitors with alternative sets of beliefs and motivations. Konstantakis et al. [26]'s work demonstrated that it is possible to provide higher quality and more relevant cultural recommendations when including information regarding the cultural background of tourists. In the context of audio tours, Shilov et al. [27] proposed automatically generated personalized audio tours based on the context and tourists' preferences. Specifically to museum visits, Kaghat et al. [28] advanced an adaptive and personalizable gesture-based audio augmented reality system.

Personalization can have an impact also in the hospitality domain: Neuhofer et al. [29] proposed a model for personalized experience co-creation between a hotel's staff and its guests, while Piccoli et al. [30] studied the benefits brought by IT-enabled 
customer service systems to service personalization, customer service perceptions, and hotel performance.

The point of view of tourists has been analyzed by Volchek et al. [31], who highlighted how personalization plays an important role but does not automatically guarantee a positive tourist experience.

In the context of tourism-related online communication, research has been conducted on the one hand, on the effectiveness of DMO's websites [32, 33] and, on the other hand, on how personalization can have a positive impact on tourism e-commerce websites, in terms of revenue [34] and customers' loyalty [35]. A lack of studies has been found for what regards email communication and marketing, more specifically newsletters, both in terms of effectiveness of the tool and personalization. Newsletters are very relevant and extensively used in the tourism domain and more and more a tool for email personalization; hence, they should be further studied. This paper wants to contribute to this gap by analyzing different audience's preferences in email marketing, as a starting point to understand how to better personalize content in DMO's newsletters making them more effective.

\section{Research Method}

The case study used for this research has been provided by Agenzia Turistica Ticinese (ATT), a regional Destination Marketing Organization active in the southern part of Switzerland. ATT has a mailing list including 50'239 contacts (data updated in April 2021). The mailing list has been shared with the researchers ensuring the anonymity of the contacts: all were shared with an anonymous ID (erasing personal data such as name and surname and email address of the contact). The indicators shared were the language that users had chosen to communicate with the DMO and their country of residence.

Table 1. Distribution of languages and related countries of the analyzed mailing list.

\begin{tabular}{l|l|l|l|l|l|l|l|l|l}
\hline \multicolumn{2}{l|}{} & CH & DE & I & FR & UK & USA & Other & Total \\
\hline \multirow{2}{*}{ DE } & Count & 16316 & 5206 & 233 & 195 & 61 & 416 & 10560 & 32987 \\
\cline { 2 - 11 } & $\%$ & $49.5 \%$ & $15.8 \%$ & $0.7 \%$ & $0.6 \%$ & $0.2 \%$ & $1.3 \%$ & $32.0 \%$ & $100.0 \%$ \\
\hline \multirow{3}{*}{ EN } & Count & 3833 & 169 & 1324 & 79 & 33 & 113 & 1875 & 7426 \\
\cline { 2 - 10 } & $\%$ & $51.6 \%$ & $2.3 \%$ & $17.8 \%$ & $1.1 \%$ & $0.4 \%$ & $1.5 \%$ & $25.2 \%$ & $100.0 \%$ \\
\hline \multirow{2}{*}{ IT } & Count & 1266 & 32 & 5 & 230 & 2 & 10 & 581 & 2126 \\
\cline { 2 - 10 } & $\%$ & $59.5 \%$ & $1.5 \%$ & $0.2 \%$ & $10.8 \%$ & $0.1 \%$ & $0.5 \%$ & $27.3 \%$ & $100.0 \%$ \\
\hline \multirow{2}{*}{ FR } & Count & 1306 & 253 & 169 & 66 & 976 & 1296 & 3634 & 7700 \\
\cline { 2 - 10 } & $\%$ & $17.0 \%$ & $3.3 \%$ & $2.2 \%$ & $0.9 \%$ & $12.7 \%$ & $16.8 \%$ & $47.2 \%$ & $100.0 \%$ \\
\hline \multirow{2}{*}{ TOT } & Count & 22721 & 5660 & 1731 & 570 & 1072 & 1835 & 16650 & 50239 \\
\cline { 2 - 9 } & $\%$ & $45.2 \%$ & $11.3 \%$ & $3.4 \%$ & $1.1 \%$ & $2.1 \%$ & $3.7 \%$ & $33.1 \%$ & $100.0 \%$ \\
\hline
\end{tabular}


Table 1 presents the distribution of languages and related countries of the analyzed mailing list. Contacts were classified according to four languages with a majority of contacts having selected German as language to communicate with the DMO, followed by English, Italian and French. Looking at the residence country: the majority of the contacts were from Switzerland, followed by Germany, Italy and France. The particular linguistic characteristics of Switzerland must be considered: in the country, there are three official languages - German, French, Italian, and a fourth national minority language: Romansh. The latter was not considered in this study as it is not a language in which ATT's newsletter is available.

In order to empirically investigate the preferences on tourism email marketing of different audiences, the following available indicator has been used: the language chosen by users to receive communications with a DMO. Language and geographical variables are indeed a criterion for customer segmentation [36, 37] and, as research suggests, online tourism promotion is not culturally neutral and should rather take into account cultural differences [38]. More precisely, studies conducted on web communication have shown the importance of studying content adaptation to the language and culture of the various audiences [39, 40]: websites that are culturally and linguistically adapted have been found to be more effective [41-43]. For these reasons, language was selected as segmentation criteria. It is important to note that in this study languages are not representing a specific country.

Email is among the main tools of direct marketing communication used by the DMO. Specifically, ATT regularly sends a newsletter to its contacts using the popular email marketing tool Mailchimp. The newsletter is sent at the beginning of each month to its mailing list and it is translated in the four languages, keeping the same structure and content for the four versions. Figure 1 presents a screenshot of part of a newsletter, where the header, main story and content module are visible. In addition to header and footer, the main body of the newsletter is generally structured as follows:

- Character story module: consists of image/video with link, title and text, call to action with link. The module is dedicated to interview stories with a local person, artisan, producer, guide, host, sport instructor, etc. presenting a peculiar activity in Ticino.

- Content modules: each module consists of an image with link, title with link and a text. On average, six content modules are present in every newsletter message.

- Event modules: not present in every newsletter, consist of images with link, title with link to upcoming events.

The links in the newsletter refer to the correspondent content pages on ATT's website, which provide more information on the topic. The links in each module are the same, for image/video and call to action in the story module and image and text in the content modules. 


\section{TICINOA}

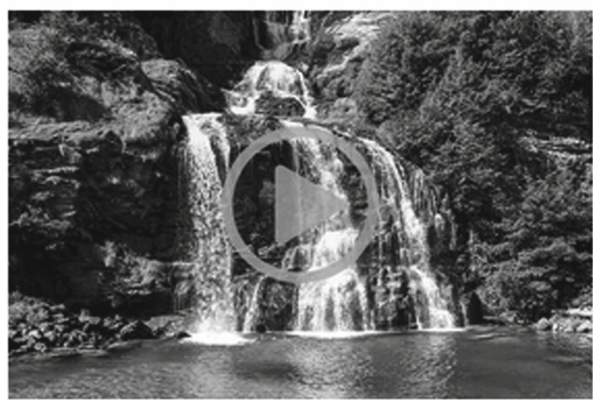

\#benvenuti

A place with a Sugarbat Mountan. Your yoga retreat in Bal. A jungle in Moxico. Or a place for connoiseours in Napa Valey. Whatevor you want to experience, experience $\mathrm{R}$ froely and sately

\section{Discover the world in Ticine}

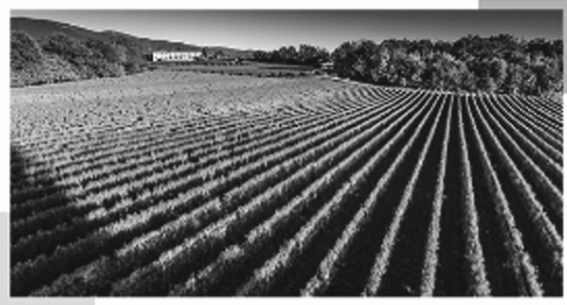

Book your hollday

Travel to Teino and beneft from our exclusive thematic offers, including overnight stays and additional services.

Fig. 1. Screenshot of part of a newsletter by ATT

For this study, it was possible to analyze the newsletters sent to ATT's mailing list from April 2018 to February 2021 in the four languages for a total of 131 analyzed newsletters (note that newsletters were never sent in January; in May 2020, three newsletter were sent; there was no data recorded for the following newsletters in the DE version: October 2018, August 2019, April 2020, in the FR version: April 2020, and EN version: April 2020). The average OR of ATT's newsletters is $30.2 \%$ (with a min. OR of $18.3 \%$ and max. of $49.1 \%$ ), which is above the tourism and hospitality industry average of $17.70 \%$ [44]. Table 3 shows the average performance of ATT's newsletter divided per language segments. In order to identify preferences in the content promoted within the newsletters, the top 10 newsletters for each language, namely the 10 newsletters with the highest OR for each language were considered (Table 2). This allowed focusing on the newsletters that received the most attention. A total of 40 newsletters were analyzed. 
Table 2. OR of the top 10 newsletters for each language

\begin{tabular}{l|l|l|l|l|l}
\hline Newsletter & DE OR (\%) & EN OR (\%) & IT OR (\%) & FR OR (\%) & Avg. OR \\
\hline April 2018 & 25.0 & $\mathbf{2 3 . 3}$ & $\mathbf{3 7 . 7}$ & 32.8 & 29.7 \\
\hline May 2018 & 24.0 & $\mathbf{2 2 . 5}$ & 32.5 & 37.3 & 29.1 \\
\hline June 2018 & 24.3 & 21.7 & 32.6 & $\mathbf{3 8 . 8}$ & 29.4 \\
\hline July 2018 & $\mathbf{2 7 . 9}$ & 21.6 & 36.6 & 36.9 & 30.8 \\
\hline August 2018 & 22.7 & $\mathbf{2 2 . 3}$ & 34.6 & 35.9 & 28.9 \\
\hline Sept. 2018 & 21.3 & $\mathbf{2 2 . 6}$ & $\mathbf{3 7 . 1}$ & 33.5 & 28.6 \\
\hline April 2019 & 26.4 & 20.8 & $\mathbf{3 8 . 6}$ & 35.9 & 30.4 \\
\hline May 2019 & 21.6 & 21.7 & $\mathbf{3 7 . 2}$ & 37.3 & 29.5 \\
\hline March 2020 & 24.1 & 20.4 & $\mathbf{3 8 . 7}$ & $\mathbf{3 9 . 7}$ & 30.7 \\
\hline April 2020 & NA & NA & $\mathbf{4 2 . 1}$ & NA & 42.1 \\
\hline 4 May 2020 & $\mathbf{3 2 . 7}$ & $\mathbf{2 7 . 0}$ & $\mathbf{4 2 . 2}$ & $\mathbf{4 9 . 1}$ & 37.8 \\
\hline 11 May 2020 & $\mathbf{3 1 . 0}$ & $\mathbf{2 4 . 0}$ & $\mathbf{3 8 . 2}$ & $\mathbf{4 4 . 4}$ & 34.4 \\
\hline 18 May 2020 & $\mathbf{3 1 . 0}$ & $\mathbf{2 7 . 8}$ & $\mathbf{3 6 . 9}$ & $\mathbf{4 4 . 4}$ & 35.0 \\
\hline June 2020 & $\mathbf{2 9 . 4}$ & $\mathbf{2 2 . 2}$ & 36.6 & $\mathbf{4 2 . 5}$ & 32.7 \\
\hline July 2020 & $\mathbf{2 6 . 8}$ & 22.0 & 32.4 & 37.7 & 29.7 \\
\hline August 2020 & $\mathbf{2 9 . 0}$ & $\mathbf{2 3 . 6}$ & 36.0 & $\mathbf{4 2 . 2}$ & 32.7 \\
\hline Sept. 2020 & $\mathbf{2 8 . 4}$ & 21.0 & 34.1 & $\mathbf{3 9 . 3}$ & 30.7 \\
\hline Oct. 2020 & 26.1 & 21.1 & 33.1 & $\mathbf{3 9 . 7}$ & 30.0 \\
\hline Dec. 2020 & $\mathbf{2 7 . 0}$ & $\mathbf{2 4 . 4}$ & 32.5 & 37.7 & 30.4 \\
\hline Feb. 2021 & $\mathbf{2 9 . 2}$ & 21.7 & $\mathbf{3 8 . 9}$ & $\mathbf{4 0 . 3}$ & 32.5 \\
\hline & & & & & \\
\hline
\end{tabular}

Table 3. Statistics of ATT's newsletter performance per language compared to industry average 2021 [44]

\begin{tabular}{l|l|l|l|l}
\hline & $\begin{array}{l}\text { OR } \\
(\%)\end{array}$ & $\begin{array}{l}\text { Bounce rate } \\
(\%)\end{array}$ & $\begin{array}{l}\text { CTR } \\
(\%)\end{array}$ & $\begin{array}{l}\text { Unsubscriptions/Successful } \\
\text { deliveries }(\%)\end{array}$ \\
\hline $\begin{array}{l}\text { Industry average } \\
2021\end{array}$ & 17.7 & - & 2.0 & 0.2 \\
\hline Newsletter DE & 25.7 & 1.3 & 4.1 & 0.6 \\
\hline Newsletter EN & 21.5 & 1.7 & 1.8 & 0.6 \\
\hline Newsletter IT & 36.1 & 1.5 & 6.9 & 0.4 \\
\hline Newsletter FR & 37.8 & 0.9 & 6.6 & 0.6 \\
\hline
\end{tabular}

The following content analysis was performed on the 40 identified top newsletters in order to understand which topics were considered as the most interesting and whether there was a difference depending on the language of the newsletter:

- The topics related to the links in the newsletter were listed, until saturation was reached.

- For each newsletter, the three most clicked links with their click rates (CR), and related topics were identified (note: images and titles have the same link in ATT's newsletter). As CR, it is here intended the percentage of clicks that a specific link in 
the newsletter has received out of all total clicks of the same newsletter (the data is provided by Mailchimp).

- The position and type of these links were also analyzed (text, photo or video) in order to understand whether there was an incidence of the link's visual characteristic, in other words, whether the most clicked links were those positioned on top of the newsletter and/or anchored to video/photo.

- For each language, the average CR of the most clicked links for each topic was calculated. The topics with the highest value were identified for each language.

\section{Results}

From the content analysis 19 topics emerged and are presented in Table 4. For each topic and for each language the average CR of the three most clicked links in the 40 newsletters analyzed is indicated. Highlighted are the three highest CR per language.

Table 4. Most clicked topics per language

\begin{tabular}{|c|c|c|c|c|}
\hline Topic & $\begin{array}{l}\text { Avg. CR of top } \\
3 \text { links DE }\end{array}$ & $\begin{array}{l}\text { Avg. CR of top } \\
3 \text { links EN }\end{array}$ & $\begin{array}{l}\text { Avg. CR of top } \\
3 \text { links IT }\end{array}$ & $\begin{array}{l}\text { Avg. CR of top } \\
3 \text { links FR }\end{array}$ \\
\hline $\begin{array}{l}\text { Ideas Ticino (top to } \\
\text { dos/must-sees) }\end{array}$ & 29.6 & 33.1 & 35.8 & 39.9 \\
\hline \multicolumn{5}{|l|}{ Ideas Christmas } \\
\hline Character Story & 20.9 & 22.7 & 14.6 & 27.5 \\
\hline $\begin{array}{l}\text { City-attraction } \\
\text { excursion }\end{array}$ & & 23.1 & & \\
\hline $\begin{array}{l}\text { Nature: discover a } \\
\text { place }\end{array}$ & 22.2 & 15.3 & 17.4 & 17.1 \\
\hline Nature: excursion & 19.1 & 20.8 & 19.9 & 21.5 \\
\hline Campaign: for hotels & 24.3 & 32 & & 28.2 \\
\hline $\begin{array}{l}\text { Campaign: COVID- } \\
\text { 19-related }\end{array}$ & 24.1 & 27.2 & 28.7 & 25.5 \\
\hline \multicolumn{5}{|l|}{$\begin{array}{l}\text { Campaign: create } \\
\text { postcard }\end{array}$} \\
\hline $\begin{array}{l}\text { Offer: discount on } \\
\text { accommodation }\end{array}$ & 25.7 & 20.9 & 16.5 & 21.7 \\
\hline Offer: families & & & 15.6 & \\
\hline Food: recipes & 17.6 & 27.1 & 13.7 & \\
\hline $\begin{array}{l}\text { Products (magazine, } \\
\text { poster) }\end{array}$ & 18.1 & 23.4 & 26.9 & 17.2 \\
\hline Events & 11.6 & 13.9 & 18.2 & 17.5 \\
\hline Sport: hiking & 29.7 & & 31.3 & 19 \\
\hline \multicolumn{5}{|l|}{ Sport: biking } \\
\hline Sport: winter & 30.9 & & 22.8 & 27.2 \\
\hline \multicolumn{5}{|l|}{ Sport: trail running } \\
\hline Sport: water & & 14.8 & & \\
\hline
\end{tabular}


In general, the topic "Ideas Ticino" (top to dos and must-sees) is the only one that had a high CR for all the languages: $29.6 \%$ for the German-speaking audience, $33.1 \%$ for the English-speaking audience, $35.8 \%$ for the Italian-speaking audience and $39.9 \%$ for the French-speaking audience. This type of content seems to be of interest throughout the different segments. With regard to the other topics, results show the presence of specificities for the different audiences divided by language in the interaction with newsletters sent by the DMO. In particular:

- For the German-speaking audience, the topics with the highest interest were winter sports (CR of 30.9\%) and hiking (29.7\%).

- For the English-speaking audience, the topics with most interest were those containing information about discounts on accommodation (32\%) and COVID-19 related campaigns $(27.2 \%)$.

- The audience indicating Italian as the language of interaction with the DMO showed a greater interest in content connected to hiking (31.3\%) and information related to the campaign COVID-19 (28.7\%).

- The French-speaking audience appeared to be interested in content regarding discounts on accommodation (28.2\%) and the character story (27.5\%).

It is also interesting to note that not all the topics appeared in the top three links of the different audiences. For example, content on city attractions was top content only for the English-speaking audience, while offers for families were top content only for the Italian-speaking audience.

Regarding the position of the most clicked content, the results suggest an incidence of link positions in the top news: the position might indeed influence users' click behavior. Results show, indeed, that the content that was placed in the first part of the newsletter, and hence required less scrolling to be visualized, was clicked more than the content in the lower part of the newsletter.

\section{Discussion}

Several insights emerged from this study. First, there is a need for case studies in tourism email marketing: the lack of literature in the tourism domain demonstrates a need for more studies for comparisons and insights on the topic. While other topics might be perceived as more "trending" or new, the role newsletters play within the everyday activities of tourism destinations call for further attention and larger studies. Second, analyses over time allow to outline trends associated with segments grouped by specific variables, in this case by language factor. In fact, while language is the considered factor here, due to the concerned DMO's practices, and due to an actual declaration of users themselves, it opens up insights on specific customers/prospects' groups. The analysis might go further and explore the drivers that attract Italians to Ticino vis-à-vis of the ones, which attract people from northern Switzerland and Germany (or Austria), or those interesting for French travelers. Moreover, info needs might be somehow disclosed also through the proxy of language: for instance, one might assume that information about COVID-19-related regulations were quite clear to Swiss travelers/prospects, while others needed to understand if travelling internationally was still possible, and under 
which conditions. Third, the actual choices related to content production and formatting can facilitate (or not) analytics. In this case, the presence of links that are divided by topic is a good way to facilitate the identification of preferences in the audience.

This study has implications also for personalization practices: such a research shows a good first step for audience segmentation and preferences' analysis in order to provide more personalized communication. The results show, indeed, that by segmenting your audience (in this case it was done according to the audience's language), different click behaviors can emerge which can be indicators of different preferences among the different segments. This study also has implications for the tourism industry: it shows the importance of implementing audience clusters in email marketing messages in order to make messages more personalized. The methodology used in this study can be applied to analyze and segment an audience, and to understand the content preferences of the different segments drawing from click behavior. This study could also be replicated using different explicit and implicit indicators for audience segmentation.

The study presents some limitations that set the stage for future research: i) the language factor is not representative of a specific region. Therefore, future research should also analyze results coming from the analysis of the country of residence to see if there are socio-cultural aspects typical of a specific region; ii) a comparison with other cases should be conducted in order to generalize results. Furthermore, having identified the 19 topics, it would be interesting to analyze who the specific audiences are for each topic. Studies on the title of the newsletters could also be conducted in order to understand whether there are different audience preferences in terms of title formats and length. Lastly, A/B tests will be conducted personalizing the content for different audiences in order to verify and validate the results of this study.

Acknowledgment. The work described in this paper was funded by the DESy (Digital Destination Evolution System) Interreg Italy-Switzerland Project.

\section{References}

1. Chaffey D, Ellis-Chadwick F, Mayer R, Johnston K (2009) Internet Marketing: Strategy, Implementation and Practice, 4th edn. Pearson Education Limited, Harlow

2. Vasudevan R (2010) E-mail marketing. J Contemp Res Manag 5(3):37-42

3. Bawm ZL, Nath RPD (2014) A conceptual model for effective email marketing. In: 17th International Conference on Computer and Information Technology (ICCIT). IEEE, Dhaka, pp 250-256

4. Morandini FS, Dobrinić D (2018) The role of segmentation in e-mail marketing. Int. J. Market Sci 1(1):145-156

5. Mailchimp: About Open and Click Rates. https://mailchimp.com/help/about-open-and-clickrates/. Accessed 11 Aug 2021

6. Mailchimp: Effects of List Segmentation on Email Marketing Stats. https://mailchimp.com/ resources/effects-of-list-segmentation-on-email-marketing-stats/. Accessed 09 Aug 2021

7. Hiziroglu A (2013) A neuro-fuzzy two-stage clustering approach to customer segmentation. J Market Analyt 1(4):202-221

8. Punhani R, Arora VPS, Sabitha S, Shukla VK (2021) Application of clustering algorithm for effective customer segmentation in E-commerce. In: 2021 International Conference on Computational Intelligence and Knowledge Economy (ICCIKE). IEE, Dubai, pp 149-154 
9. Hiziroglu A, Sengul S (2012) Investigating two customer lifetime value models from segmentation perspective. Procedia Soc Behav Sci 62(2012):766-774

10. Litmus: State of Email Report 2020. The data, trends, and innovations that shape successful email programs in 2020- and the decade to come. https://www.litmus.com/resources/state-ofemail/. Accessed 09 Aug 2021

11. Campaign Monitor: The Power of Email Personalization to Reach Humans (Not Just Inboxes). https://www.campaignmonitor.com/resources/guides/personalized-email/. Accessed 09 Aug 2021

12. Phan QAH (2019) Personalization in Email Marketing - Case Study: Debic Brand at FrieslandCampina. Karelia University of Applied Sciences

13. Jackson TW (2007) Personalisation and CRM. Datab Market Cust Strategy Manag 15 (1):24-36

14. Vesanen J (2007) What is personalization? A conceptual framework. Eur J Mark 41 (5/6):409-418

15. Chen X, Liu Q, Qiao X (2020) Approaching another tourism recommender. In: 2020 IEEE 20th International Conference on Software Quality, Reliability and Security Companion (QRS-C). IEEE, Macau, pp 556-562

16. Ricci F, Rokach L, Shapira B (eds) (2015) Recommender Systems Handbook. Springer, Boston. https://doi.org/10.1007/978-1-4899-7637-6

17. Missaoui S, Kassem F, Viviani M, Agostini A, Faiz R, Pasi G (2019) LOOKER: a mobile, personalized recommender system in the tourism domain based on social media usergenerated content. Pers Ubiquit Comput 23(2):181-197

18. Amer-Yahia S, Borromeo RM, Elbassuoni S, Omidvar-Tehrani B, Viswanathan S (2020) Interactive generation and customization of travel packages for individuals and groups. In: Proceedings of the 25th International Conference on Intelligent User Interfaces Companion (IUI 2020). Association for Computing Machinery, New York, pp 69-70

19. De Carolis B, Lops P, Cataldo M, Semeraro G (2020) Towards a social robot as interface for tourism recommendations. In: Proceedings of the Workshop on Adapted intEraction with SociAl Robots, cAESAR 2020, Cagliari, pp 28-33

20. Wang X (2020) Personalized recommendation framework design for online tourism: know you better than yourself. Ind Manag Data Syst 120(11):2067-2079

21. Ravi L, Subramaniyaswamy V, Vijayakumar V, Jhaveri RH, Shah J (2021) Hybrid user clustering-based travel planning system for personalized point of interest recommendation. In: Sahni M, Merigó JM, Jha BK, Verma R (eds) Mathematical Modeling, Computational Intelligence Techniques and Renewable Energy, vol 1287. AISC. Springer, Singapore, pp 311-321. https://doi.org/10.1007/978-981-15-9953-8_27

22. Choi Y, Ryu YU, Kim JK (2021) A recommender system based on personal constraints for smart tourism city. Asia Pacific J Tour Res 26(4):440-453

23. Chen C, Zhang S, Yu Q, Ye Z, Ye Z, Hu F (2021) Personalized travel route recommendation algorithm based on improved genetic algorithm. J Intell Fuzzy Syst 40(3):4407-4423

24. Ribeiro F, Metrôlho J, Leal J, Martins H, Bastos P (2018) A mobile application to provide personalized information for mobility impaired tourists. In: Rocha Á, Adeli H, Reis LP, Costanzo S (eds) WorldCIST'18 2018, vol 746. AISC. Springer, Cham, pp 164-173. https:// doi.org/10.1007/978-3-319-77712-2_16

25. Ross D (2020) Towards meaningful co-creation: a study of creative heritage tourism in Alentejo, Portugal. Curr Issues Tour 23(22):2811-2824

26. Konstantakis M, Alexandridis G, Caridakis G (2020) A personalized heritage-oriented recommender system based on extended cultural tourist typologies. Big Data Cognit Comput $4(2): 12$ 
27. Shilov N, Kashevnik A, Mikhailov S (2018) Context-aware generation of personalized audio tours: approach and evaluation. In: Karpov A, Jokisch O, Potapova R (eds) SPECOM 2018, vol 11096. LNCS (LNAI). Springer, Cham, pp 615-624. https://doi.org/10.1007/978-3-31999579-3_63

28. Kaghat F, Azough A, Fakhour M, Meknassi M (2020) A new audio augmented reality interaction and adaptation model for museum visits. Comput Electr Eng 84:106606

29. Neuhofer B, Buhalis D, Ladkin A (2015) Smart technologies for personalized experiences: a case study in the hospitality domain. Electron Mark 25(3):243-254. https://doi.org/10.1007/ s12525-015-0182-1

30. Piccoli G, Lui T, Grün B (2017) The impact of IT-enabled customer service systems on service personalization, customer service perceptions, and hotel performance. Tour Manag 59:349-362

31. Volchek K, Law R, Buhalis D, Song H (2019) The good, the bad, and the ugly: tourist perceptions on interactions with personalised content. e-Rev Tour Res 16(2/3), 62-72

32. Park YA, Gretzel U (2007) Success factors for destination marketing web sites: a qualitative meta-analysis. J Travel Res 46(1):46-63

33. Drosopoulou C, Malama E-I, Patsioura F, Vlachopoulou M (2015) Evaluating destination marketing organizations' websites: conceptual and empirical review. In: Information Resources Management Association (ed.) Hospitality, Travel, and Tourism: Concepts, Methodologies, Tools, and Applications. IGI Global, pp 250-262

34. Khai DL, Das D (2020) Data mining and personalization for smart travel management. J Crit $\operatorname{Rev} 7(3): 66-73$

35. Martínez-González JA, Álvarez-Albelo CD (2021) Influence of site personalization and first impression on young consumers' loyalty to tourism websites. Sustainability 13(3):1425

36. Hughes AM (2006) Strategic Database Marketing, 3rd edn. McGraw-Hill, New York

37. Kotler P, Keller KL, Martinović M (2012) Marketing Management, 14th edn. MATE, Zagreb

38. Mele E, Cantoni L (2017) Localization of national tourism organizations websites: the case of ETC members. In: Schegg R, Stangl B (eds) Information and communication technologies in tourism. Springer, Cham, pp 59-71

39. Cappelli G (2008) The translation of tourism-related websites and localization: problems and perspectives. In: Baicchi A (ed) Voices on Translation. RILA Rassegna Italiana di Linguistica Applicata. Bulzoni Editore, Roma, pp 97-115

40. Achkasov VA (2015) Words under pressure: translation in the context of search engine optimization. J Siberian Federal Univ Human Soc Sci 8(2):200-208

41. Tixier M (2005) Globalization and localization of contents: evolution of major Internet sites across sectors of industry. Thunderbird Int Bus Rev 47(1):15-48

42. Singh N, Fassott G, Chao M, Hoffmann J (2006) Understanding international web site usage: a cross-national study of German, Brazilian, and Taiwanese online consumers. Int Mark Rev 23(1):83-98

43. Baack DW, Singh N (2007) Culture and web communications. J Bus Res 60(3):181-188

44. Campaign Monitor: Ultimate Email Marketing Benchmarks for 2021: By Industry and Day. https://www.campaignmonitor.com/resources/guides/email-marketing-benchmarks/. Accessed 12 Aug 2021 
Open Access This chapter is licensed under the terms of the Creative Commons Attribution 4.0 International License (http://creativecommons.org/licenses/by/4.0/), which permits use, sharing, adaptation, distribution and reproduction in any medium or format, as long as you give appropriate credit to the original author(s) and the source, provide a link to the Creative Commons license and indicate if changes were made.

The images or other third party material in this chapter are included in the chapter's Creative Commons license, unless indicated otherwise in a credit line to the material. If material is not included in the chapter's Creative Commons license and your intended use is not permitted by statutory regulation or exceeds the permitted use, you will need to obtain permission directly from the copyright holder.

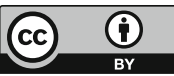

